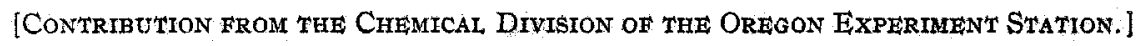

\title{
NITROGEN COMPOUNDS IN ALFALFA HAY.
}

\author{
By HARRY G. MILIER.
}

Received August 22, 1921.

In an earlier paper results were reported on the distribution of nitrogen in the alfalfa seed. A similar study has now been made on a sample of alfalfa hay, although this phase of the investigation was begun before the work on nitrogen distribution in the seed was undertaken. The difficulty of separating the nitrogen compounds in the alfalfa hay prompted the writer to apply certain analytical methods to the seed to obtain information as to what nitrogen compounds might be present in the leaves and stems of the alfalfa plant. Results of the study to ascertain the nitrogen groups in alfalfa hay, while not complete, are reported in this paper, due to a discontinuance of this work for a year.

The sample of hay was grown in eastern Oregon and was cut at a time when the hay, according to agricultural practice, is best suited for feeding purposes. It contained $1.98 \%$ of nitrogen. Extracting $25 \mathrm{~g}$. of finely ground alfalfa with ether followed by alcohol and then water in a Soxhlet extractor removed the following amounts of nitrogen given as percentages of the total nitrogen; ether, $0.85 \%$; alcohol $(95 \%), 5.32 \%$; and water, $34.5 \%$. In all $40.7 \%$ of the total nitrogen was removed. The residue from extraction weighed $15.71 \mathrm{~g}$. and contained $1.86 \%$ of nitrogen. By difference, the solids dissolved would weigh $9.29 \mathrm{~g}$. and contain $2.18 \%$ of nitrogen. In cold water $39.0 \%$ of the total nitrogen was soluble, $10 \%$ sodium chloride solution extracted an additional $9.8 \%$ and this followed by $0.2 \%$ potassium hydroxide solution brought the total up to $58.1 \%$. Extracting directly with $0.2 \%$ potassium hydroxide solution removed $58 \%$ of the nitrogen of which $53 \%$ was precipitated with acetic acid leaving $27.3 \%$ of the total nitrogen in solution. Hot water extraction removed $28.7 \%$; however, when this residue was further extracted with the potassium hydroxide solution only $4.5 \%$ of the total nitrogen was brought into solution compared to about $31 \%$ before. - Heating the residue to the boiling point of water apparently changed the nature of the alkali-soluble nitrogen compounds. A $0.5 \%$ potassium hydroxide solution extracted more nitrogen from alfalfa which had been ground fine enough to pass through a 40 -mesh sieve than from ordinary chopped alfalfa for feeding purposes. After the proteins were removed from these extracts the nitrogen content of the filtrates was the same, representing $27.7 \%$ of the total nitrogen. As an example $4 \mathrm{~g}$. each of coarse and fine alfalfa were extracted with $0.5 \%$ potassium hydroxide solution; the total amounts of nitrogen extracted were $0.0325 \mathrm{~g}$. and $0.0465 \mathrm{~g}$. respectively. The weights of nitrogen precipitated as protein were $0.0111 \mathrm{~g}$. from the coarse material and 
$0.0246 \mathrm{~g}$. from the finely ground sample, leaving as non-protein $0.0214 \mathrm{~g}$. and $0.0219 \mathrm{~g}$. respectively. A cold-water extract of the fine material after removing the protein with acetic acid contained $28 \%$ of the total nitrogen, while a hot-water extract of the coarse alfalfa contained $27.8 \%$ of the nitrogen. Apparently there are certain nitrogen compounds which are very easily extracted with hot water, cold water or alkali, and after removing the protein from the two latter solutions the percentages of nonprotein nitrogen extracted are the same regardless of the degree of fineness of the alfalfa. Alkali extracted about $100 \%$ more protein from the finer particles than from the chopped alfalfa.

Mixing the alfalfa flour with water and $0.5 \%$ potassium hydroxide solution and placing the sealed containers in a freezing mixture of ice and salt $\left(-20^{\circ}\right)$ did not cause more nitrogen to be extracted, but rather less; the water solution contained $29.2 \%$ of the total nitrogen and the alkali extract $40.8 \%$. Subjecting a $3 \mathrm{~g}$. sample of alfalfa to the crude fiber determination did not extract all of the titrogen, as $7.3 \%$ still remained. The dilute sulfuric acid $(1.25 \%)$ removed only $8.5 \%$, while the following sodium hydroxide solution $(1.25 \%)$ extracted $49.1 \%$. The preceding extraction with ether and water removed $0.9 \%$ and $30 \%$ nitrogen, respectively. The $4.2 \%$ not accounted for was most probably removed as ammonia in the sodium hydroxide digestion.

\section{Protein Nitrogen.}

A preparation of protein for applying the Van Slyke method to determine certain nitrogen groups was obtained by extracting the alfalfa with $0.5 \%$ potassium hydroxide solution. Nearly all the extract was obtained by using a press. The solution after filtering was acidified with either acetic or hydrochloric acid to precipitate the protein. The protein was then extracted with absolute alcohol in a Soxhlet extractor until the extract was practically colorless, the alcohol was washed out with ether and the protein dried in a vacuum desiccator over sulfuric acid. Analysis showed for nitrogen, $12.9 \%$; for sulfur, $0.85 \%$; and for ash, $1.27 \%$. No preparation of protein contained over $13 \%$ of nitrogen in spite of repeated precipitation and thorough alcohol extraction. After the protein was dried it would not dissolve in alkali in the cold and only with difficulty in an alcoholicalkali solution $(50.0 \mathrm{cc}$. of alcohol $+50 \mathrm{cc}$. of $1 \%$ potassium hydroxide solution). Decomposition of the protein took place in the latter process.

After this work had been completed, Dowell and Menau1 ${ }^{1}$ reported results on nitrogen distribution of some proteins obtained by dilute alkali extraction. The protein they obtained from alfalfa contained $13.6 \%$ nitrogen $(0.85 \times 0.16)$. Chibnall and Schryver2 obtained proteins from the green leaves of cabbage, spinach, bean, grass, etc., by extracting with water, using ether as a cytolytic agent. Their products sepa-

${ }^{1}$ Dowell and Menaul, J. Biol. Chem., 46, 437 (1921).

Chibnall and Schryver, Biochem. $J_{n}, 15,60$ (1921). 
rated on warming this solution to $40^{\circ}$. When freshly prepared they were soluble in weak alkaline solutions from which they could be precipitated by acids. They contained about $13 \%$ of nitrogen. A protein preparation obtained by Osborne and Wakeman $^{3}$ from green spinach leaves contained $15.3 \%$ of nitrogen. They ground the fresh leaves with water, centrifuged out the cellular matter, after which they precipitated a substance containing $14 \%$ nitrogen. This was brought into solution with alkali and another precipitate obtained by adding acid which contained $15.3 \%$ nitrogen. This corresponds more nearly to nitrogen content of protein from seeds while in the results reported from the other workers the nitrogen content of the proteins in the leaves averages about $13.0 \%$.

Results of analysis of the protein by the Van Slyke method are given in the following table. 'Two portions of Sample I weighing $3.2856 \mathrm{~g}$. and $3.6353 \mathrm{~g}$., equivalent to 0.4230 and $0.4681 \mathrm{~g}$. of nitrogen, were hydrolyzed. for 20 hours with $20 \%$ hydrochloric acid; $3.31 \mathrm{~g}$. of Sample II, containing $0.4145 \mathrm{~g}$. of nitrogen, was hydrolyzed for 30 hours. The percentage nitirogen distribution of the protein of the seed reported in an earlier paper $s$ given in the last column for comparison. So far as the writer knows there are no other data showing a comparison of the nitrogen distribution between a seed protein and the protein existing in the stems and leaves of the same plant, both obtained by the same method.

TABLE I.

ANalysis of Proteln from Alfalfa Hax by the Van Slyke Method.

\begin{tabular}{|c|c|c|c|c|c|c|c|c|}
\hline & & Sam! & le $I$. & & Sampl & e II. & & $\begin{array}{l}\text { Protein } \\
\text { from } \\
\text { Seed. }\end{array}$ \\
\hline Form of Nitrogen. & & $\%$ & G. & $\%$. & G. & $\%$ & A.v. $\%$. & . Av. \%. \\
\hline Amide..... & 0.0266 & 6.15 & 0.0280 & 5.98 & 0.0266 & 6.41 & 6.18 & 8.67 \\
\hline $\begin{array}{l}\text { Humin, adsorbed } \\
\text { by lime.......... }\end{array}$ & 0.0227 & 5.36 & 0.0210 & 4.49 & 0.0211 & 5.09 & $6.11^{a}$ & 4,41 \\
\hline $\begin{array}{l}\text { Humin, insoluble in } \\
\text { amyl alcohol..... }\end{array}$ & 0.0005 & 0.01 & 0.0025 & 0.53 & 0.0017 & 0.40 & & $\cdots$ \\
\hline $\begin{array}{l}\text { Humin, in amyl al- } \\
\text { cohol extract..... }\end{array}$ & 0.0032 & 0.75 & 0.0062 & 1.32 & 0.0015 & 0.38 & $\ldots \ldots$ & $\cdots$ \\
\hline Arginine........ & 0.0585 & 13.83 & 0.0625 & 13.25 & 0.0592 & 14.28 & 13.82 & 21.38 \\
\hline Histidine. . & 0.0110 & 2.60 & 0.0170 & 3.63 & 0.0156 & 3.76 & 3.33 & 5.42 \\
\hline Iyysine . . . . . . . . & 0.0525 & 12.41 & 0.0493 & 10.53 & 0.0422 & 10.18 & 11.04 & 6.11 \\
\hline Cystine.......... & 0.0040 & 0.95 & 0.0039 & 0.90 & 0.0040 & 0.90 & 0.91 & 1.01 \\
\hline Amino, filtrate.... & 0.2345 & 55.44 & 0.2603 & 55.61 & 0.2358 & 56.88 & 55.98 & 47.87 \\
\hline Non-amino, filtrate. & 0.0096 & 2.27 & 0.0096 & 2.05 & 0.0117 & 2.82 & 2,38 & 5.32 \\
\hline Total recovered ${ }^{b} \ldots$ & 0.4231 & 99.77 & 0.4603 & 98.39 & 0.4192 & 101.10 & 99.75 & 100.19 \\
\hline
\end{tabular}

An explanation as to why the nitrogen content of the leaf protein (13.0\%) was lower than that of seed protein $(15.6 \%)$ may be found in these data. The protein from the seed yielded a larger quantity of the basic amino acids

"Osborne and Wakeman, J. Biol. Chem., 42, 1 (1920).

"Plimmer, "The Chemical Constitution of the Proteins. I. Analysis," Longmans, Green and Company, 1917, p. 107. 
than the leaf protein; especially is this significant in the arginine content of the two proteins. Calctlating the weight of arginine present from the above nitrogen distribution, $1 \mathrm{~g}$. of seed protein contains $0.1032 \mathrm{~g}$. of arginine, while the same weight of leaf protein contains $0.0558 \mathrm{~g}$. of arginine. As arginine contains more nitrogen than any other amino acid thus far isolated, its replacing other amino acid groups in the protein molecule or direct addition to the same would increase the nitrogen content of the protein. Of course low arginine content does not mean low nitrogen content of the protein or vice versa, which is shown in tables ${ }^{6}$ giving the nitrogen distribution in proteins. However, as further evidence will be given, analytical results show that there is an increase in concentration of the arginine group to total nitrogen as the nitrogen compounds pass from the leaves into the seed and this may explain the higher nitrogen content of the seed protein over the leaf protein. Distribution of nitrogen in the hydrolytic products of the whole alfalfa seed reported in the earlier paper ${ }^{6}$ shows that $14.98 \%$ of the total nitrogen reacted as arginine nitrogen, and that this could all be calculated as coming from the protein present in the seed. Grindley, Joseph and Slater ${ }^{7}$ report $7.68 \%$ arginine in the hydrolytic products of alfalfa hay. This compared with the arginine content of the seed shows the large difference in arginine concentration. In the Van Slyke method of determining arginine in the hydrolytic products of alfalfa hay and the whole seeds there may be other nitrogen compounds present liberating ammonia when boiled with the alkali solution, thus giving a higher arginine content than the actual amount present. This does not appear to be the case with alfalfa seed for reasons already mentioned. With hay this undoubtedly takes place as will be shown later in the discussion of the water-soluble nitrogen compounds, which would make the difference between the actual ratio of arginine to total nitrogen greater than the above figures show. Roxas ${ }^{8}$ found that arginine gave up $2.3 \%$ of its nitrogen for humin formation; this reaction would have a tendency to lower the actual arginine nitrogen in the solution, although it should not interfere seriously with the above results.

Chibnall and Schryver ${ }^{2}$ state that the protein isolated from cabbage was acidic in properties and on hydrolysis yielded an amount of ammonia corresponding to $5 \%$ of the total nitrogen. They comment as follows: "T"Wese results indicate that acidic proteins exist in the leaves, which when they pass into the resting stage in the seed, undergo amidization. Such proteins should contain a relatively small amount of nitrogen." The higher percentage of anide nitrogen in the seed protein compared to the

${ }^{5}$ Ref: 4, p. 107.

' Miller, This Journal, 43, 906 (1921).

'Grindley, Joseph and Slater, ibid., 37, 1778 (1915).

8 Roxas, J. Biol. Chem., 27, 71 (1916). 
leaf protein recorded in the above table gives support to this view. It appears logical to assume from the presence of these groups with a high nitrogen concentration in the seed protein and the appreciable quantities of ammonium salts and other soluble nitrogen compounds in the green plant that as the plant matures these simple nitrogen compounds are gradually incorporated into the protein molecule, thus increasing the nitrogen content of the latter. The spinach used by Osborne and Wakeman may have reached a more advanced stage of maturity than the sample used by Chibnall and Schryver and on the above assumption should contain more nitrogen. No study has yet been made pertaining to the equilibrium existing between ammonium salts, amino acids and proteins during different stages of growth. A study of this kind would help solve the problem. The possibility of the leaf protein being combined with a nitrogen-poor prosthetic group must not be overlooked and the larger yield of humin nitrogen from the leaf protein may be due to a group of this nature. The percentage distribution of the nitrogen groups in the protein from alfalfa obtained by Dowell and Menaul ${ }^{1}$ varies somewhat from our results. This is probably due to a different compound, the difference being caused by the isolation of the protein at a different stage of growth.

\section{The Water-Soluble Nitrogen Compounds.}

As indicated before there was a certain class of nitrogen compounds, not protein, easily extracted with hot water, cold water or dil. alkali. Little is known of the nature of these non-protein nitrogen compounds. Hart and Bently, ${ }^{9}$ in their work on the character of water soluble nitrogen compounds in feeding stuffs determined the ammonia nitrogen, amide nitrogen and amino nitrogen. Steenbock ${ }^{10}$ isolated stachydrin from a hot-water extract of alfalfa hay. Following the same method the writer was unable to obtain any stachydrin hydrochloride from the sample of alfalfa hay used in this investigation. In removing the purines by precipitating with silver nitrate in dil. nitric acid solution a heavy flocculent precipitate formed. A similar precipitate formed with silver nitrate in an ammoniacal solution. A portion of the solution obtained from the phosphotungstic acid precipitate of the water extract of alfalfa, which reacted strongly alkaline, was slightly acidified with nitric acid and $5 \%$ silver nitrate added until a test portion gave a brown precipitate with barium hydroxide. The resulting precipitate was filtered off, washed and suspended in warm water. Hydrogen sulfide was passed in to remove the silver as silver sulfide, and the filtrate was boiled to remove excess of hydrogen sulfide. A portion of this filtrate did not give the color reaction for the murexide test. Adenine and hypoxanthine do not respond to this test. ${ }^{11}$ A portion of the solid obtained by allowing

${ }^{3}$ Hart and Bentley, J. Biol. Chem, 22, 477 (1915).

${ }^{10}$ Steenbock, ibid., 35, 1 (1918).

11 Walter Jones, "Nucleic Acids," Longmans, Green and Company, 1914, pp. 89, 95. 
the above filtrate to evaporate gave the characteristic ruby-red coloration with hydrochloric acid, zinc and sodium hydroxide. ${ }^{12}$ Hypoxanthine and adenine give this test. A purine precipitate was obtained again by precipitating with small quantities of solid silver sulfate in the solution. slightly acidified with sulfuric acid. The sulfuric acid alone gave no precipitate, so that the alkalinity of the solution or the carbon dioxide evolved could not be attributed to the presence of barium hydroxide or carbonate not removed. The silver precipitate was suspended in water to which a few drops of hydrochloric acid were added. This solution was made ammoniacal, the precipitate filtered off and thoroughly washed. It was then suspended in nitric acid, 1.10 sp. gr., and boiled. Particles of silver chloride were filtered off and the filtrate was allowed to stand for 24 hours. Small orange colored crystals separated, weighing $0.0780 \mathrm{~g}$. and containing $23.50 \%$ of nitrogen. Nitrogen calculated in the hypoxanthine salt of silver nitrate corresponding to the formula $\mathrm{C}_{5} \mathrm{H}_{4} \mathrm{ON}_{4} . \mathrm{AgNO}_{3}$ is $22.88 \%$.

Aeration of water extract of alfalfa removed ammonia equal to $2.0 \%$ of the total nitrogen. After hydrolyzing with $10 \%$ hydrochloric acid for 10 hours, the clear extract, after filtering off the humin nitrogen, yielded ammonia nitrogen by aeration equal to $3.75 \%$ of the total nitrogen, and amino nitrogen equivalent to $14.0 \%$ of the total nitrogen.

In preparing the phosphotungstic precipitates used in this work, the quantity of the acid required to precipitate the basic nitrogenous compounds was exceedingly great when compared to the amount required in the hydrolyzed solution of the protein. A quantity of extract containing $0.4287 \mathrm{~g}$. of nitrogen was hydrolyzed with $10 \%$ hydrochloric acid for 10 hours. This was then treated in the same way as in the Van Slyke method of protein analysis. Fifteen $\mathrm{g}$. of phosphotungstic acid which precipitates the basic amino acids from protein containing the same amount of nitrogen did not precipitate all the compounds that form precipitates with the acid from this hydrolyzed water extract. A further addition of $200 \mathrm{cc}$. $(15 \mathrm{~g}$. of phosphotungstic acid per $100 \mathrm{cc}$.) did not precipitate all the above compounds after 48 hours' standing. 'The precipitates formed by further separate additions of two $50 \mathrm{cc}$. quantities were filtered off and the total nitrogen determined. The first contained $6.16 \mathrm{mg}$. of nitrogen, and the second $5.0 \mathrm{mg}$. These results show what small proportions of nitrogen, the nature of which permits its precipitation by phosphotungstic acid, are removed by a large quantity of the acid, especially when compared to a hydrolyzed protein solution.

The residues obtained from decomposing the phosphotungstate precipitates with barium hydroxide and removing the excess of barium, as

12 Allen, "Commercial Organic Analysis," P. Blakiston's Son and Co., 1913, Vol. 7, p. 335 . 
the carbonate never contained over $3.5 \%$ nitrogen. Using a similar water extract made alkaline with sodium carbonate, and adding mercuric chloride solution, a precipitate was obtained, which, after removing the mercury with hydrogen sulfide and evaporating the solution to dryness, left a residue containing $13 \%$ nitrogen. The high concentration of nitrogen in the residue from the mercury precipitation was partly due to ammonium salts. The phosphotungstic precipitate was decomposed in an alkaline solution and later heated when the carbon dioxide was passed in. This process would free the ammonia while the mercury precipitate was decomposed in an acid solution.

In order to compare the mercuric chloride and phosphotungstic acid precipitations, $1000 \mathrm{cc}$. of water extract from $200 \mathrm{~g}$. of alfalfa hay was treated with a $20 \%$ lead acetate solution until no further precipitate formed. Excess of lead in the filtrate was removed by adding sodium carbonate in excess. After filtering off the lead carbonate this alkaline solution was heated in a water-bath in an evaporating dish for 12 hours to drive off the ammonia, and made up to $1000 \mathrm{cc}$. To a $200 \mathrm{cc}$. portion, $20 \mathrm{~g}$. of mercuric chloride was added and the mixture warmed to dissolve all the chloride. Another $200 \mathrm{cc}$. portion was acidified with sulfuric acid to $5 \%$ strength and $200 \mathrm{cc}$. of a $20 \%$ phosphotungstic acid solution in $5 \%$ sulfuric acid was added. After 24 hours the precipitates were decomposed in the usual way. The mercury precipitate dissolved in dil. hydrochloric acid with the formation of a white crystalline salt which contained no nitrogen and was filtered off before the hydrogen sulfide was passed in. The residue from the mercury precipitate weighed $0.79 \mathrm{~g}$. and contained $8.83 \%$ of nitrogen; the phosphotungstic acid residue weighed $1.02 \mathrm{~g}$. and contained $3.3 \%$ of nitrogen. Time did not permit a comparison of the total quantity of nitrogen removed when phosphotungstic acid was added until no further precipitate formed. Excess of mercury was present in the above precipitation.

The precipitate formed by the addition of lead acetate was decomposed with dil. sulfuric acid and the total nitrogen determined in the filtrate from lead sulfate; $2.75 \%$ of the total nitrogen in alfalfa or $9.82 \%$ of the non-protein nitrogen was precipitated by lead acetate. Twenty per cent. of the nitrogen from the lead precipitate was given off as ammonia when boiled with $25 \%$ potassium hydroxide, which, calculated as arginine nitrogen, would be $40 \%$ of the nitrogen in the lead precipitate. The mercury precipitate contained $8.88 \%$ of the total nitrogen. The residue from the mercury precipitate was dissolved in water and the total nitrogen determined on precipitates obtained by adding silver sulfate to the solution slightly acidified with sulfuric acid, and when it was rendered alkaline with barium hydroxide. The purine fraction contained $36 \%$ of the total nitrogen and the histidine-arginine fraction $35 \% ; 3.2 \%$ of the total nitrogen 
was in the purine fraction. Whether all of this fraction is composed of purines would have to be determined by analysis; this amount of nitrogen separated in the purine fraction by following the analytical procedure recommended. ${ }^{13}$ The presence of these purines would increase the percentage of arginine as determined by the Van Slyke method on hydrolyzing the whole alfalfa hay. This was pointed out by Brewster and Alsberg $^{14}$ in their work with yeast nucleic acid.

\section{Summary.}

1. Certain non-protein nitrogen compounds composing about $28 \%$ of the total nitrogen were easily extracted with water regardless of the degree of fineness of the alfalfa hay.

2. Alkali extracted more protein from the finely ground material than from the coarse.

3. The protein from alfalfa hay extracted by dilute alkali, had a nitrogen content of $13.0 \%$ and contained the basic amino acids arginine, histidine, lysine and cystine.

4. The protein from the seed yielded larger quantities of arginine and amide nitrogen than the leaf protein, which may account for the difference in the total nitrogen of the two proteins.

5. The purine fraction contained $3.2 \%$ of the total nitrogen. A crystalline salt corresponding to the nitrogen content of hypoxanthine silver nitrate was obtained.

6. Mercuric chloride precipitation of the water extract gave a residue high in nitrogen after removing the mercury, apparently suitable for further investigation pertaining to the nitrogen compounds in alfalfa hay.

CoRvalits, OrEgon. p. 120 .

18 Barger, "The Simpler Natural Bases," Longmans, Green and Company, 1914,

${ }^{14}$ Brewster and Alsberg, J. Biol, Chem., 37, 367 (1919), 